\title{
Insulin induced hypoglycaemia in migraine
}

\author{
JOHN PEARCE \\ From the Combined Neurological Service, Hull Royal Infirmary, Hull
}

SUMMARY Insulin induced hypoglycaemia produced migrainous symptoms in only two of $2 \underset{\vec{F}}{\vec{F}}$ migraine sufferers and in none of a matched control group. The relationship of fasting and blooф sugar levels to migraine attacks is discussed.

It has long been known that attacks of migraine may be precipitated in susceptible subjects by hunger and the absence of food. Critchley and Ferguson (1933) drew attention to this relationship, stating that 'missing a meal or unwonted exercise on an empty stomach might cause an attack'. Blau and Cumings (1966) investigated this relationship by fasting 12 migraine subjects for 19 hours, and measuring blood sugar levels at intervals during this period. Six of these subjects developed migraine, 11 to 14 hours after the beginning of the fast. The lowest blood sugar levels varied from 44 to $77 \mathrm{mg} / \mathrm{ml}$. More recently, Blau and Pyke (1970) have noticed that the frequent migraine attacks may disappear with the advent of diabetes, and that nocturnal hypoglycaemia reactions may be important triggers for migraine attacks in certain diabetics.

The nature of the relationship between blood sugar levels and the occurrence of migraine attacks has not however been elucidated precisely. The blood sugar levels recorded by Blau and Cumings (1966) in the fasting state, though low, are not abnormal. This suggests the possibility that the absolute blood sugar value is not itself the critical factor, and that the rate of fall may be more important.

As part of a more extensive investigation into the hypothalamic-pituitary-adrenal axis in migraine subjects (Rao and Peace, 1971) the insulin hypoglycaemia test (Jasani, Boyle, Greig, Dalakos, Browning, Thompson, and Buchanan, 1967) has been performed as a sensitive index of the integrity of this axis. This has afforded us the opportunity of comparing the clinical and blood sugar responses, in migraine and control subjects, to insulin induced hypoglycaemia.

\section{METHODS}

Thirty volunteers were studied. The selection was weighted in favour of females because of their higher prevalence rate for migraine. Ten subjects were norma healthy controls whose age ranged from 22 to 39 years (eight female and two male). Twenty migraine patient $\overrightarrow{\mathbf{s}}$ (17 female and three male) were studied whose agesw ranged from 22 to 48 years. All the selected migraine subjects suffered from classical migraine (Pearce, 1969 with a defined visual or sensory aura.

A venous blood sample was taken for plasma cortiso and blood sugar estimations. An Argyle Medicut intraî venous 18 gauge canula was inserted at 9.00 a.m. का was kept in situ for further collection of samples. The first specimen was withdrawn at this time, and a secon basal sample was obtained 30 minutes later. At this pointsoluble insulin $0.15 \mathrm{u} . / \mathrm{kg}$ body weight was injected through the canula. Samples were collected thereaftepas half hourly intervals for two hours. Venous blood sugar was estimated by the Technicon auto-analyser metho using alkaline-ferricyanide.

Throughout the period of the test patients were kept under continuous clinical observation.

\section{RESULTS}

Table 1 shows the results of blood sugar estimations on two occasions before and 30 minutes after the्ठ injection of intravenous insulin in the contro $B$ subjects. Table 2 shows the results in 20 migraine subjects. The mean and standard deviations fo? venous blood sugar levels did not differ significantlys on statistical analysis in the control and migraine groups. The degree of hypoglycaemia produced waso of moderate severity with mean values of 24.3 $\mathrm{mg} / 100 \mathrm{ml}$. and $20.4 \mathrm{mg} / 100 \mathrm{ml}$. in the control anळ migraine patients respectively.

All the control subjects tolerated the test without unusually severe side-effects. Feelings of faintness, sweating, palpitations, and minor degrees of sub음 jective dizziness and difficulty in concentration were commented on by most subjects. There was no case of serious impairment of conscious level or of epilepsy, and in no patient was the administration of intravenous glucose necessary. 
TABLE 1

INSULIN HYPOGLYCAEMIA TEST-CONTROLS

\begin{tabular}{cccccc}
\hline No. & Age & Sex & \multicolumn{2}{c}{ Blood sugar mg/100 ml. } \\
\cline { 4 - 6 } & & & $\begin{array}{c}-30 \\
(\text { min })\end{array}$ & 0 & $\begin{array}{r}+30 \\
(\text { min })\end{array}$ \\
\hline 1 & 39 & F & 73 & 73 & 17 \\
2 & 35 & M & 75 & 67 & 48 \\
3 & 25 & F & 80 & 77 & 25 \\
4 & 39 & F & 84 & 70 & 28 \\
5 & 29 & F & 80 & 85 & 26 \\
6 & 22 & M & 65 & 56 & 19 \\
7 & 20 & F & 93 & 92 & 16 \\
8 & 36 & F & 77 & 77 & 13 \\
9 & 28 & F & 65 & 70 & 13 \\
10 & 35 & F & 79 & 78 & 38 \\
\hline Mean & 32 & & $77 \cdot 1$ & $74 \cdot 5$ & $24 \cdot 3$ \\
SD & & & 9 & $9 \cdot 7$ & $10 \cdot 8$ \\
\hline
\end{tabular}

TABLE 2

INSULIN HYPOGLYCAEMIA TEST-MIGRAINE SUBJECTS

\begin{tabular}{|c|c|c|c|c|c|}
\hline \multirow[t]{2}{*}{ No. } & \multirow[t]{2}{*}{ Age } & \multirow[t]{2}{*}{ Sex } & \multicolumn{3}{|c|}{ Blood sugar $\mathrm{mg} / 100 \mathrm{ml}$. } \\
\hline & & & $\begin{array}{c}-30 \\
(\mathrm{~min})\end{array}$ & 0 & $\begin{array}{c}+30 \\
(\mathrm{~min})\end{array}$ \\
\hline 1 & 48 & F & 49 & 48 & 26 \\
\hline 2 & 35 & $\mathbf{F}$ & 69 & 65 & 10 \\
\hline 3 & 29 & $\mathbf{F}$ & 60 & 50 & 10 \\
\hline 4 & 41 & F & 71 & 65 & 9 \\
\hline 5 & 30 & $\mathbf{F}$ & 80 & 80 & 20 \\
\hline 6 & 44 & $\mathbf{F}$ & 62 & 66 & 19 \\
\hline 7 & 46 & $\mathbf{M}$ & 53 & 57 & 10 \\
\hline 8 & 22 & $\mathrm{~F}$ & 85 & 83 & 25 \\
\hline 9 & 30 & $\mathbf{F}$ & 85 & 86 & 35 \\
\hline 10 & 25 & $\mathbf{F}$ & 61 & 63 & 24 \\
\hline 11 & 38 & F & 68 & 57 & 20 \\
\hline 12 & 45 & $\mathbf{F}$ & 78 & 73 & 15 \\
\hline 13 & 45 & $\mathbf{F}$ & 63 & 70 & 12 \\
\hline 14 & 30 & $\mathrm{~F}$ & 65 & 68 & 24 \\
\hline 15 & 47 & $\mathbf{M}$ & 71 & 72 & 17 \\
\hline 16 & 45 & $\mathbf{M}$ & 82 & 75 & 16 \\
\hline 17 & 23 & $\mathbf{F}$ & 77 & 70 & 15 \\
\hline 18 & 31 & F & 75 & 75 & 30 \\
\hline 19 & 45 & $\mathrm{~F}$ & 100 & 89 & 18 \\
\hline 20 & 28 & $F$ & 66 & 68 & 52 \\
\hline $\begin{array}{l}\text { Mean } \\
\text { SD }\end{array}$ & 36 & & 71 & 69 & $20 \cdot 35$ \\
\hline
\end{tabular}

Of the 20 migraine subjects, 18 tolerated the procedure with symptoms identical with those in the control group, and without significant headache or focal neurological symptoms.

One patient (subject 12) developed a classical migraine attack 30 to 45 minutes after the administration of the insulin. This was a 45 year old woman who development bilateral teichopsiae in the periphery of the visual fields accompanied by unilateral throbbing headache, nausea, and vomiting. This pattern of symptoms was identical with her normally spontaneously occurring attacks. One other patient (subject 18) developed typical spreading fortification spectra in the fields of vision, accompanied by feelings of faintness, sweating, and a sense of mental remoteness. These symptoms developed 30 minutes after intravenous insulin but were not followed by headache. These visual symptoms persisted for 60 minutes and then faded gradually.

\section{COMMENT}

These findings indicate that both control and most migraine subjects can tolerate a highly significant degree of insulin induced hypoglycaemia without developing headache or migraine. None of the control subjects, and only one $(5 \%)$ of the migraine subjects developed headache. All of the migraine patients at the time of investigations had been experiencing frequent spontaneously occurring migraine attacks, with a frequency of one attack every one to six weeks. They therefore could not be considered to be in a state of remission. None of the migraine subjects had just recovered from an attack within the preceding 48 hours, at which time some degree of resistance to migraine is encountered and patients tend to be less vulnerable to the usual precipitating factors (Pearce, 1968).

It would appear that (1) a rapid fall in blood sugar of approximately $50 \mathrm{mg} / 100 \mathrm{ml}$. in 30 minutes and (2) moderately severe hypoglycaemia are sufficient to induce migrainous symptoms in only occasional migraine patients. This factor presumably was significant in the two subjects who did develop migraine attacks during hypoglycaemia, but this clearly is an uncommon pattern of reaction.

It would therefore appear that migraine attacks induced by hunger or fasting are unlikely to be directly related to the absolute blood sugar levels at this time. Nor from the present results does it seem likely that such attacks are related to the rapidity of fall in the venous blood sugar. Other and probably more complex metabolic factors have to be invoked, and these are currently under investigation.

The author is indebted to Dr. N. S. Rao and to Mr. J. Parkes and his colleagues for their assistance in this study. Part of this investigation was supported by the British Migraine Trust.

\section{REFERENCES}

Blau, J. N., and Cumings, J. N. (1966). Methods of precipitating and preventing some migraine attacks. Brit. med.J., 2, 1242-1243.

Blau, J. N., and Pyke, D. A. (1970). Effect of diabetes on migraine. Lancet, 2, 241-243. 
Critchley, M., and Ferguson, F. R. (1933). Migraine. Lancet, $1,123-126$ and 182-187.

Jasani, M. K., Boyle, J. A., Greig, W. R., Dalakos, T. G., Browning, M. C. K., Thompson, A., and Buchanan, W. W. (1967). Corticosteroid-induced suppression of the hypothalamo-pituitary-adrenal axis: observations on patients given oral corticosteroids for rheumatoid arthritis. Quart. J. Med., 36, 261-276.
Pearce, J. (1968). The ophthalmological complications of migraine. J. Neurol. Sci., 6, 73-18.

Pearce, J. (1969). Migraine; Clinical Features, Mechanisms and Management. Thomas: Springfield, Ill.

Rao, N. S., and Pearce, J. (1971). Hypothalamic-pituitary adrenal axis studies in migraine with special reference to insulin sensitivity. Brain. (In press.) 